\title{
Head Up Games: The Games of the Future Will Look More Like the Games of the Past
}

\author{
Iris Soute and Panos Markopoulos \\ Faculty of Industrial Design, Eindhoven University of Technology, \\ P.O. Box 513, 5600 MB Eindhoven, The Netherlands \\ \{i.a.c.soute, p.markopoulos\} @tue.nl
}

\begin{abstract}
With the emergence of pervasive technology, pervasive games came into existence. Most are location-aware applications, played with a PDA or mobile phone. We argue that the interaction paradigm these games support, limits outdoor play that often involves spontaneous social interaction. This paper introduces a new genre of pervasive games we call Head Up Games. The paper describes these games and how they differ from current research prototypes of pervasive games. Also, it outlines their characteristics and illustrates our vision with Camelot, an outdoor game for children.
\end{abstract}

Keywords: Pervasive games, Children, Social gaming.

\section{Introduction}

Computer games are often criticized for reducing players to interact with their fingers, sitting still at a screen, having limited possibilities for social interactions. With the development of pervasive technology the genre of pervasive games has emerged: "[a] genre in which traditional, real-world games are augmented with computing functionality, or, depending on the perspective, purely virtual computer entertainment is brought back to the real world" 4]. We are interested in outdoor games for children, with the emphasis on social gaming: i.e. games that support and stimulate social interaction between players.

There has been a wealth of pervasive games reported in related literature. Examples of outdoor games for adults are Uncle Roy All Around You 1 and Catchbob! 6]. These games are location-based games, played with a GPS and/or Wifi device. Mobile players use a small display (PDA or mobile phone) to show location and game-related information. Fewer cases exist of pervasive outdoor games specifically designed for children: two pioneering examples are Savannah [2, and Ambient Wood [7. In Savannah, children were equipped with PDA's with WiFi and GPS. A virtual savannah was overlaid on a school field, and children had to cooperate as "lions" to hunt the savannah. In Ambient Wood, children took a field trip in a wood that was augmented with mobile and fixed devices that provided contextually-relevant information. Each pair of children carried a PDA and a probe. The games mentioned above share three characteristics:

- Location Bound Infrastructure. The game narrative is supported by a location-specific investment of installation and maintenance of hardware, e.g., 
placing the devices in the forest for Ambient Wood. One may expect that in the future both the hardware and the infrastructure will be more readily available but for the time being creating such a mixed reality game narrative remains an expensive undertaking requiring considerable expertise and effort. Moreover, assuming such infrastructure exists does not mean that spontaneous play at locations such as playgrounds, parks etc. becomes possible.

- Location awareness. All games assume a form of location awareness. However, GPS errors can adversely influence the game play, as has been noted in Savannah 2]. Nova et al. 6] report that players that used the automated location awareness tool did not perform better than other participants.

- PDA as gaming platform. Interactions with the virtual world are performed through a portable display, that acts as a window to the virtual world. This mode of interaction competes with the interaction between players and the physical world. Instead of looking at each other children have to walk head down attending to their devices.

\section{Traditional and Head Up Games}

Perhaps a good way to start discussing traditional outdoor children's games is by referring to a 16th century painting by Bruegel called 'Children's Games' 1 . Many of the games depicted are still played today, e.g.: tag, hide and seek or ball games. Traditional games have features in common: they require physical activity, and are played with little materials (like a ball, or a skipping cord). As these games are played with multiple players and are played in the same physical space, traditional games promote social interaction. Finally, the rules of traditional games are often few and simple. It is our assertion that it is feasible to transfer some, or all, of the features of traditional games to pervasive games and that this would lead to enjoyable and sociable gaming experiences.

Currently, the settings where children play games also mark a clear separation in the type of games that are played. Outdoor games require physical activity; indoor games are mostly played sitting down at a computer. We advocate a new class of games merging aspects of both worlds: games that can be played outdoors, requiring physical activity, and are enhanced by technology. We argue that these types of games should make minimal use of handheld displays, as this forces children to abandon physical activity; looking down on a screen, does not go together with wildly running around. Hence the name of the games: Head Up Games (HUGs). The defining characteristics of HUGs are:

- Technology and game design. Technology must be simple and work reliably so that its usage becomes transparent. We accept the argument that limitations (seams) 3] exist in most forms of technology and designers ought to address them, but we feel that current research prototypes in the field of pervasive gaming have focused too much on exploring the potential of new technologies rather than serving the purposes of game design. Simpler

${ }^{1}$ See http://www.khm.at/staticE/page2121.html 
and more robust technologies can support pervasive gaming for children adequately, avoiding the pitfalls relating to technology imperfections.

- Minimal installation. If we look at current outdoor games, we see that the toys used are easy to bring along, and play with anywhere, anytime. We should keep this in mind when applying technology in HUGs.

- Imagination vs. visualization of virtual worlds. Traditional play relies heavily on a child's imagination: e.g., a broom stick can easily turn into a horse. Vygotsky (in [8]) stresses the importance of symbolic play, i.e. without explicit visualizations, as this presumably lays the foundation for development of abstract thinking. Furthermore, using location awareness and PDA's to connect virtual to real worlds neglects alternative possibilities such as the use of sensors to sense motion, proximity, or contact, opening up a richer foray of interactions. In HUGs we aim to investigate these alternative possibilities.

- Rich, social interaction. In many multi-player computer games social interaction is limited to online chat, i.e. using the keyboard to convey messages. With HUGs, like traditional games, we aim to have children use a broader range of social interactions, like spoken language and body language.

\section{Camelot}

Camelot 9] represents a first attempt to design a head up game. It was developed over a course of 4 months, and during development it was repeatedly evaluated with a group of 10 children between 7 to 10 year old (see Figure 1). In Camelot children compete in two teams to build a castle. To this end, the teams have to gather different types of resources that are spread around in zones on the play field. The first team to complete the castle wins the game. Randomly during the game, a ghost appears and tries to steal resources from the teams.

No display technologies were used in Camelot. Instead, small devices (collectors) were designed to acquire resources from the zones. For communication purposes, each collector and zone was equipped with infrared technology. Hence, there was no need for a centralized computer system. The collectors weighed very little and were easy to run around with for the children. Also, the zones
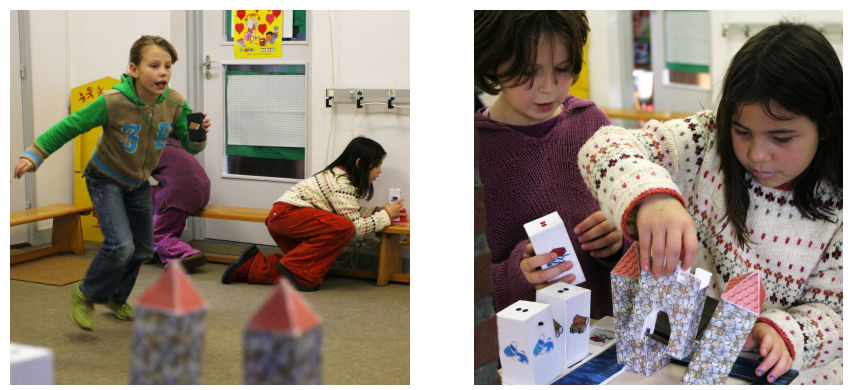

Fig. 1. Photos of the evaluation of Camelot with children in their school gym 
were portable, so the game could be played anywhere. As Camelot was played in teams, players needed to discuss tactics to win the game. This automatically led to social interaction between the players. The evaluations showed that fun came from the social interaction, the competition between the teams but also the suspense added by the unpredictable appearance of the ghost.

\section{Discussion and Conclusion}

In his motivation for "La Casa Prossima Futura" [5], Marzano envisioned that with ambient intelligence technology: "The home of tomorrow will look more like the home of yesterday than the homes of today". This paper has sketched HUGs as an analogue to Marzano's vision in the world of pervasive games, where currently fun appears to be subordinate to concerns for the operation of technology. After the initial fascination with pervasive technology, the scene is set for designing games that provide entertainment in ways familiar, in settings where games have always been played and supporting the patterns of play that have traditionally been found when children meet outdoors to play together. We have argued in favor of this vision and outlined what we believe to be the defining characteristics for Head Up Games. We have discussed Camelot, an example of such a game. In our future research we plan to design more instances of HUGs in order to explore their possibilities and limitations.

\section{References}

1. Benford, S., Seager, W., Flintham, M., Anastasi, R., et al.: The Error of Our Ways: The Experience of Self-Reported Position in a Location-Based Game. In: Mynatt, E., Siio, I. (eds.) UbiComp 2004. LNCS, vol. 3205, pp. 70-87. Springer, Heidelberg (2004)

2. Benford, S., Rowland, D., Flintham, M., Drozd, et al.: Life on the edge: supporting collaboration in location-based experiences. In: CHI '05, pp. 721-730. ACM Press, New York (2005)

3. Chalmers, M., Bell, M., Brown, B., Hall, M., Sherwood, S., Tennent, P.: Gaming on the edge: using seams in ubicomp games. In: ACE '05, pp. 306-309. ACM Press, New York (2005)

4. Magerkurth, C., Cheok, A.D., Mandryk, R.L., Nilsen, T.: Pervasive games: bringing computer entertainment back to the real world Comput. Entertain. vol. 3, ACM Press, New York (2005)

5. Marzano, S.: True Visions: The Emergence of Ambient Intelligence. In: Aarts, E., Encarnacã, J. (eds.) Ambient Culture, Ch. 3., pp. 35-52. Springer, Heidelberg (2006)

6. Nova, N., Girardin, F., Molinari, G., Dillenbourg, P.: The Underwhelming Effects of Automatic Location-Awareness on Collaboration in a Pervasive Game. In: International Confernce on Cooperative Systems Design, pp. 224-238 (2006)

7. Rogers, Y., Price, S., Fitzpatrick, G., Fleck, R., et al.: Ambient wood: designing new forms of digital augmentation for learning outdoors. In: IDC '04, pp. 3-10. ACM Press, New York (2004)

8. Verenikina, I., Harris, P., Lysaght, P.: Child's play: computer games, theories of play and children's development. In: CRPIT '03, Australian Comp. Soc (2003)

9. Verhaegh, J., Soute, I., Kessels, A., Markopoulos, P.: On the design of Camelot, an outdoor game for children. In: IDC '06, pp. 9-16. ACM Press, New York (2006) 